\title{
A multicentre, randomised, controlled trial to assess the safety, ease of use, and reliability of hyaluronic acid/carboxymethylcellulose powder adhesion barrier versus no barrier in colorectal laparoscopic surgery
}

Stéphane V Berdah ${ }^{1 *}$, Christophe Mariette ${ }^{2}$, Christine Denet ${ }^{3}$, Yves Panis $^{4}$, Christophe Laurent ${ }^{5}$, Eddy Cotte ${ }^{6}$, Nöel Huten ${ }^{7}$, Eliane Le Peillet Feuillet ${ }^{8}$ and Jean-Jacques Duron ${ }^{9}$

\begin{abstract}
Background: Intra-peritoneal adhesions are frequent following abdominal surgery and are the most common cause of small bowel obstructions. A hyaluronic acid/carboxymethylcellulose (HA/CMC) film adhesion barrier has been shown to reduce adhesion formation in abdominal surgery. An HA/CMC powder formulation was developed for application during laparoscopic procedures.

Methods: This was an exploratory, prospective, randomised, single-blind, parallel-group, Phase Illb, multicentre study conducted at 15 hospitals in France to assess the safety of HA/CMC powder versus no adhesion barrier following laparoscopic colorectal surgery. Subjects $\geq 18$ years of age who were scheduled for colorectal laparoscopy (Mangram contamination class I-III) within 8 weeks of selection were eligible, regardless of aetiology. Participants were randomised 1:1 to the HA/CMC powder or no adhesion barrier group using a centralised randomisation list. Patients assigned to HA/CMC powder received a single application of 1 to $10 \mathrm{~g}$ on adhesion-prone areas. In the no adhesion barrier group, no adhesion barrier or placebo was applied. The primary safety assessments were the incidence of adverse events, serious adverse events, and surgical site infections (SSIs) for 30 days following surgery. Between-group comparisons were made using Fisher's exact test.

Results: Of those randomised to the HA/CMC powder $(n=105)$ or no adhesion barrier $(n=104)$ groups, one patient in each group discontinued prior to the study end (one death in each group). Adverse events were more frequent in the HA/CMC powder group versus the no adhesion barrier group (63\% vs. $39 \% ; P<0.001$ ), as were serious adverse events ( $28 \%$ vs. $11 \% ; P<0.001)$. There were no statistically significant differences between the HA/ CMC powder group and the no adhesion barrier group in SSIs (21\% vs. 14\%; $P=0.216)$ and serious SSIs (12\% vs. 9\%; $P=0.38$ ), or in the most frequent serious SSIs of pelvic abscess ( $5 \%$ and $2 \%$; significance not tested), anastomotic fistula (3\% and $4 \%$ ), and peritonitis (2\% and $3 \%$ ).
\end{abstract}

Conclusions: This exploratory study found significantly higher rates of adverse events and serious adverse events in the HA/CMC powder group compared with the no adhesion barrier group in laparoscopic colorectal resection.

Trial registration: ClinicalTrials.gov NCT00813397. Registered 19 December 2008.

Keywords: Adhesion barrier, Colorectal surgery, Laparoscopy, Surgical adhesions, Surgical site infection

\footnotetext{
* Correspondence: stephane.berdah@ap-hm.fr

${ }^{1}$ Chirurgie Digestive, Hôpital Nord, CERC (Centre d'Enseignement et de Recherche Chirurgical), Aix-Marseille Université, Chemin des Bourrellys, 13915

Marseille, Cedex 20, France

Full list of author information is available at the end of the article
}

\section{Biomed Central}

(c) 2014 Berdah et al.; licensee BioMed Central Ltd. This is an Open Access article distributed under the terms of the Creative Commons Attribution License (http://creativecommons.org/licenses/by/4.0), which permits unrestricted use, distribution, and reproduction in any medium, provided the original work is properly credited. The Creative Commons Public Domain Dedication waiver (http://creativecommons.org/publicdomain/zero/1.0/) applies to the data made available in this article, unless otherwise stated. 


\section{Background}

Intra-peritoneal adhesions are estimated to occur after $93 \%$ to $100 \%$ of upper abdominal laparotomies and after $67 \%$ to $93 \%$ of lower abdominal laparotomies [1]. Adhesions form as a result of surgical trauma or infection/ inflammation, and comprise fibrous scar tissue that abnormally connects tissues and organs [2]. They are the most common cause of small bowel obstructions [3-6] and are associated with infertility and possibly chronic pain. Adhesions may also prolong operating time in subsequent surgery, and cause complications such as unintentional enterotomy $[2,6-8]$.

There is no effective treatment for adhesions, and surgery to deal with the consequences of adhesions, such as small bowel obstruction, often results in further adhesion formation $[1,2]$. Adhesion prevention should therefore be considered the best management strategy [2,9], although this is not widely demonstrated in the literature. A good surgical technique (e.g., minimal tissue trauma, avoiding introduction of foreign materials) can reduce adhesion formation, but is not sufficient for prevention $[2,9]$. Adhesions may be reduced by using laparoscopy versus open surgery [10-12], which results in a reduction in adhesion-related complications, such as small bowel obstruction, but does not totally prevent adhesion formation [6]. A number of anti-adhesion products are available for adjuvant use during surgery, with various formulations including films, fabrics, gels, and fluids. These products act as a temporary mechanical barrier to separate organs and tissues for a short time while healing takes place. Despite the number of agents available worldwide, few have demonstrated efficacy in reducing post-surgical adhesions, and limited conclusions can be drawn on the effect of reducing adhesions, as no agent has been shown to improve the myriad negative outcomes commonly associated with adhesions [13].

In abdominal surgery, a hyaluronic acid/carboxymethylcellulose (HA/CMC) film adhesion barrier has been shown to reduce adhesion formation with a favourable safety profile [13-17]. A powder formulation of HA/ CMC (HA/CMC powder; Sepraspray ${ }^{\mathrm{mm}}$ Adhesion Barrier, Genzyme Corp., Cambridge, MA, USA) was developed for application during laparoscopic procedures. Preclinical animal models indicated that this formulation was effective in reducing adhesion formation and did not disrupt normal wound healing $[18,19]$. In a randomised pilot study in women undergoing laparoscopic myomectomy, there was a trend towards a reduction in adhesions with HA/CMC powder versus no adhesion barrier, with a favourable safety profile [20]. The primary objective of this study was to assess the safety of HA/CMC powder versus no adhesion barrier following laparoscopic colorectal and/or small bowel surgery (high risk for morbidity [21]), as determined by the incidence of adverse events, serious adverse events, superficial surgical site infections (SSIs) and deep SSIs, such as fistula, sepsis, abscess, and peritonitis.

\section{Methods}

This was an exploratory, prospective, randomised, singleblind, parallel-group, Phase IIIb, multicentre study conducted at 15 hospitals in France (ClinicalTrials.gov Identifier: NCT00813397). The study comprised a selection visit 1 to 56 days prior to the planned surgery (Day 0 ) and two postoperative follow-up assessments (day of discharge or $7 \pm 3$ days post-surgery, and end-of-study assessment 28 to 35 days post-surgery). This follow-up duration was based on postoperative guidelines on infections [22] and the knowledge that HA/CMC is resorbed from the peritoneal cavity within 7 days and fully eliminated from the body in $<28$ days [23].

The study was carried out in compliance with the Declaration of Helsinki and the principles of the French Good Clinical Practice regulations/clinical research guidelines. The protocol and patient consent forms were approved by an independent ethics committee (reference number 208 R09, Sud-Méditerranée II, Marseille, France). All patients signed an informed consent form. An independent review committee of four independent experts was established to provide real-time expert review of safety reports and assess all safety data at study end.

\section{Participants}

Men and women $\geq 18$ years of age were eligible if they were scheduled to undergo a laparoscopic colorectal and/ or small intestine surgical resection of Mangram contamination class I, II, or III [22] within 8 weeks of selection, whatever the aetiology (including cancer). Participants were also required to have an American Society of Anesthesiologists Physical Status Classification of P1, P2, or P3 and women of childbearing potential were required to use an effective contraceptive method for 1 month after randomisation. The principal exclusion criteria were cancer requiring chemotherapy and/or radiotherapy within 30 days prior to or after surgery; current abdominal abscess and/or peritonitis; pregnancy; clinically significant cardiovascular, hepatic, neurologic, psychiatric, endocrine, or other major systemic disease that would interfere with the study or jeopardize patient outcomes within 30 days; and treatment with heparinic anticoagulants (except prophylaxis for deep vein thrombosis).

Additional exclusion criteria applied at the time of surgery were use of another medical device that may interfere with the study (e.g., prosthetic stitch, biological adhesive, haemostatic compress, surgical membrane, or physical barrier to prevent adherence); infection discovered in the abdominal cavity; change to Mangram contamination class IV; and conversion to laparotomy 
(although mini laparotomy was permitted, based on standard laparoscopic approaches in colorectal surgery).

\section{Treatment}

Participants were randomised to the HA/CMC powder or no adhesion barrier group during the planned surgical procedure (Day 0) in a 1:1 ratio using a centralised randomisation list and an automated Interactive Voice Response System, following re-evaluation of their eligibility. Patients were blinded to their randomisation group throughout the study.

Patients assigned to $\mathrm{HA} / \mathrm{CMC}$ powder received a single application to adhesion-prone areas but not to anastomoses or sutures. HA/CMC powder was applied with a single-use applicator attached to a sprayer to allow precise application to the required sites while minimizing potential dispersion to other sites. The amount applied was at the surgeon's judgement, and ranged from 1 to $10 \mathrm{~g}$, with the maximum determined based on a previous study of HA/CMC film [24]. In patients assigned to the no adhesion barrier group, no adhesion barrier or placebo was applied. In both groups, closure of trocar sites was performed according to the normal routine of the surgeon; peritoneal closure was not performed.

\section{Safety assessments}

The primary objective of this study was to compare the incidence of adverse events, serious adverse events, superficial (incisional) SSIs, and deep SSIs in the HA/CMC powder and no adhesion barrier groups for 30 days following surgery. Any suspected intra-abdominal abscess was investigated by CT-scan/MRI. Any suspicion of sepsis was confirmed by at least one positive blood culture and specific symptoms. Any suspicion of peritonitis was confirmed by positive bacterial cultures from peritoneal swabs of drainage during interventional radiology or surgery. All such SSIs were followed up until resolution. In the HA/ CMC powder group, the relationship of adverse events to treatment was judged by investigators as not related, unlikely, possibly, probably, or definitely related. Events that were routinely observed during the postoperative period (e.g., pain, nausea, vomiting) were not reported as an adverse event unless they occurred with unusual severity according to the investigator's judgement, or required unusual or specific management.

The duration of hospitalisation after surgery was noted along with intraoperative parameters and perioperative parameters. Exposure to $\mathrm{HA} / \mathrm{CMC}$ powder was determined from the amount of powder applied (grams) and duration of application (minutes).

\section{Ease of use, manageability, and reliability assessments} Ease of use was evaluated by the surgeon using a 4-point scale $(1=$ very difficult, 2 =difficult, 3 =easy, $4=$ very easy). HA/CMC powder was considered manageable if this item was scored 3 or 4 . The ease of attaching the applicator to the sprayer and introducing the HA/CMC powder into the sprayer was assessed by the nurse in charge of surgical instruments in the operating room using the same 4-point scale. HA/CMC powder was considered manageable if both items were scored 3 or 4 . Reliability was assessed by the surgeon based on the ability to cover all target areas, apply a homogeneous layer, and deliver the suitable amount of HA/CMC powder using a 4-point scale ( 1 = very bad, 2 = bad, $3=$ good, $4=$ very good), with HA/CMC powder being considered reliable if each item was scored 3 or 4 .

\section{Statistical analysis}

As the study was exploratory, no sample size calculation was performed. Safety analyses were performed on the safety population, comprising all randomised patients who underwent surgery. Surgical and ease of use analyses were performed on the intent-to-treat population, described as all randomised patients who received treatment during surgery as determined by randomisation.

Safety data are reported in summary tables and betweengroup comparisons made using Fisher's exact test. Descriptive statistics are provided for ease of use, manageability, and reliability.

A post-hoc analysis of risk factors for deep SSIs and serious adverse events was carried out. Logistic regression was performed for each covariate. The univariate model included treatment effect, covariate effect, and the effect for the interaction between treatment and the covariate. Covariates included gender, age, body mass index, smoking status, smoking frequency, use of drains, adhesiolysis, and type of anastomosis, among others. A significance level of 0.10 (deep SSIs) or 0.20 (serious adverse events) was used to select the individual covariates to be included in the final multivariate model for the backwards stepwise logistic regression analysis. The odds ratio (OR) and 95\% confidence intervals (CI) were calculated.

\section{Role of the sponsor}

The study sponsor was involved in the design of the study. Data were collected by investigators at each site. Patient randomisation and data management were carried out by a research organisation contracted by the study sponsor. Together with the study investigators, the sponsor participated in the analysis and interpretation of data, the writing of the manuscript, and the decision to submit the manuscript for publication.

\section{Results}

The study was carried out between September 2008 and July 2009. Patient disposition is summarized in Figure 1. 


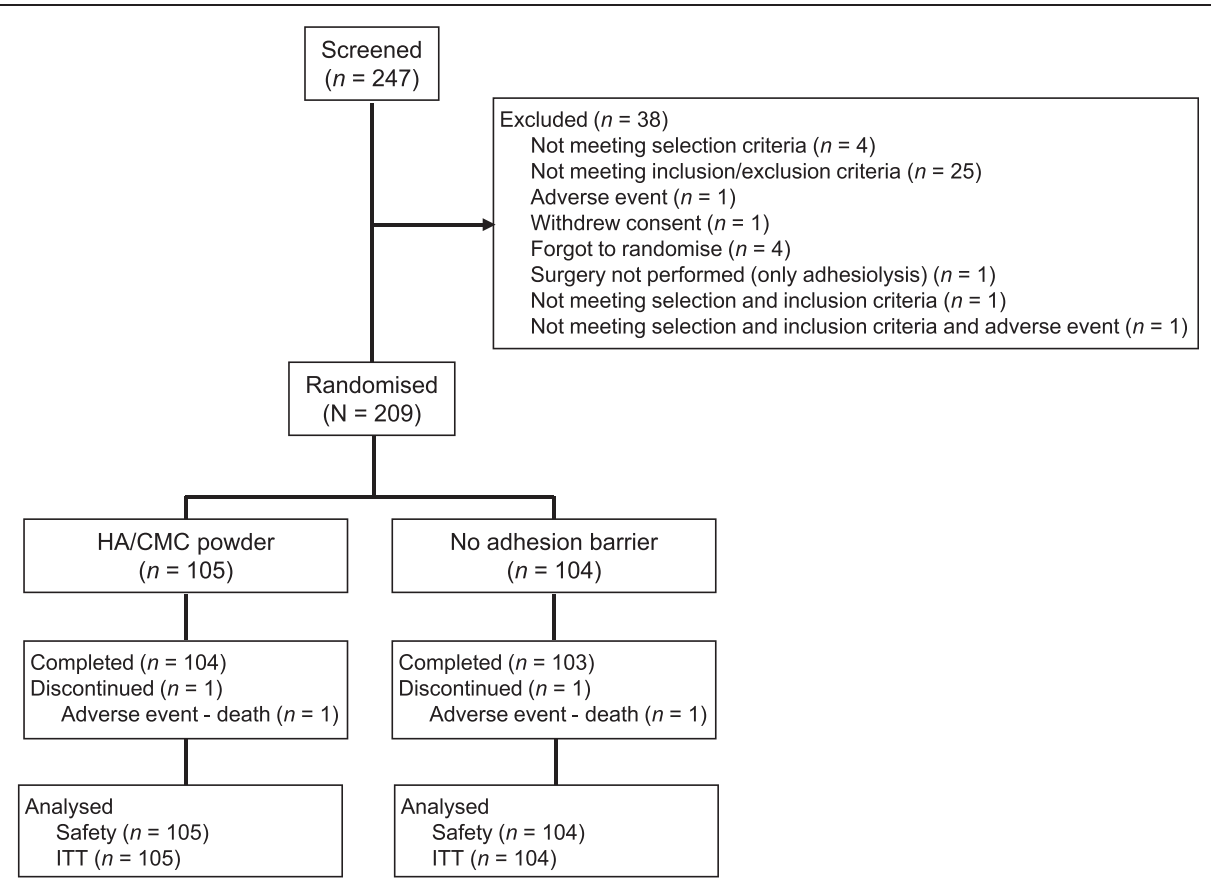

Figure 1 Patient disposition. ITT, intent-to-treat.

Of 209 patients randomised to the HA/CMC powder $(\mathrm{n}=105)$ or the no adhesion barrier $(\mathrm{n}=104)$ groups, only one patient in each group discontinued prior to study end (one death in each group). Patient characteristics and medical history were similar (Table 1), except for a lower frequency of patients with concomitant allergic diseases $(P=0.031)$ and a higher frequency of patients taking concomitant penicillin combinations (significance not tested) in the HA/CMC powder group versus no adhesion barrier. Previous or concomitant immunosuppressive drugs were taken by $7 / 105$ (7\%) patients in the HA/CMC powder group and 12/104 (12\%) patients in the no adhesion barrier group $(P=0.221)$, and corticosteroids by $15 / 105$ (14\%) and 22/104 (21\%) patients, respectively $(P=0.193)$. Within the year prior to study randomisation (but not within 30 days before surgery), 10/105 (19\%) of patients in the HA/CMC powder group and 7/104 (15\%) in the no adhesion barrier group had received abdominal or pelvic radiotherapy $(P=0.666)$, and $9 / 105(17 \%)$ and $8 / 104(17 \%)$, respectively, had received chemotherapy $(P=0.958)$. Intraoperative parameters were comparable between groups (Table 2$)$, although adhesiolysis $(P=0.073)$ and manual anastomosis $(P=0.034)$ were performed more frequently in the HA/CMC powder group.

There were no differences between the HA/CMC powder and no adhesion barrier groups in perioperative findings (Table 3) except for number of drains used $(P=0.021)$ and mean duration of surgery $(P=0.419)$.

\section{Safety outcomes}

Adverse events, serious adverse events, and deaths are summarized in Table 4. One patient in each group had an adverse event leading to death: septic shock stemming from aspiration pneumonia in the HA/CMC powder group, and septic shock and multiorgan failure in the no adhesion barrier group; for the patient in the $\mathrm{HA} / \mathrm{CMC}$ powder group, the investigator assessed the adverse event as not related to treatment.

The overall frequency of adverse events was significantly higher in the HA/CMC powder versus the no adhesion barrier group (66/105 [63\%] vs. 41/104 [39\%]; $P<0.001)$. The overall frequency of serious adverse events was significantly higher in the HA/CMC powder group compared with the no adhesion barrier $(P<0.001)$.

Overall, 10/105 (10\%) patients in the HA/CMC powder group experienced at least one adverse event that was considered by the investigator as possibly, probably, or definitely related to the investigational product: abdominal pain $(n=2)$, flatulence $(n=2)$, ileus $(n=1)$, impaired gastric emptying $(n=1)$, intestinal obstruction $(n=1)$, abdominal abscess $(n=2)$, intestinal abscess $(n=1)$, incision site abscess $(n=1)$, anastomotic fistula $(n=1)$, incision site haemorrhage $(n=1)$, and postoperative ileus $(n=1)$. The frequency of treatment-related serious adverse events in the HA/CMC powder group was $4 \%$ (4/105 patients), and these were ileus $(n=1)$ and the SSIs of abdominal abscess $(n=2)$, intestinal abscess $(n=1)$, incision site abscess $(n=1)$, and anastomotic fistula $(n=1)$. As this 
Table 1 Patient characteristics and medical history at baseline (intent-to-treat population)

\begin{tabular}{|c|c|c|c|}
\hline & HA/CMC powder $(n=105)$ & No adhesion barrier $(n=104)$ & $P$ value \\
\hline Age in years, mean $\pm S D$ & $57.6 \pm 16.3$ & $56.1 \pm 16.5$ & 0.531 \\
\hline Men, n (\%) & $53(50.5)$ & $51(49.0)$ & 0.835 \\
\hline $\mathrm{BMI}$ in $\mathrm{kg} / \mathrm{m}^{2}$, mean $\pm \mathrm{SD}$ & $24.7 \pm 4.0$ & $24.3 \pm 4.2$ & 0.451 \\
\hline Smoking history, n (\%) & & & 0.676 \\
\hline Current smoker & $16(15.8)$ & $18(17.8)$ & \\
\hline Ex-smoker & $19(18.8)$ & $23(22.8)$ & \\
\hline Non-smoker & $66(65.3)$ & $60(59.4)$ & \\
\hline Previous abdominal/pelvic surgery, n (\%) & $58(55.2)$ & $61(58.7)$ & 0.618 \\
\hline Diabetes, n (\%) & $10(9.6)$ & $5(4.8)$ & 0.180 \\
\hline Pre-operative diagnosis, n (\%) & & & 0.566 \\
\hline Cancer & $48(45.7)$ & $44(42.3)$ & \\
\hline Diverticulosis & $27(25.7)$ & $36(34.6)$ & \\
\hline Crohn's disease & $11(10.5)$ & $7(6.7)$ & \\
\hline Ulcerative colitis & $5(4.8)$ & $7(6.7)$ & \\
\hline Polyp (no cancer) & $5(4.8)$ & $5(4.8)$ & \\
\hline Other & $5(4.8)$ & $1(1.0)$ & \\
\hline Endometriosis & $2(1.9)$ & $3(2.9)$ & \\
\hline Polyposis & $2(1.9)$ & $1(1.0)$ & \\
\hline ASA Physical Status classification, n (\%) & & & 0.537 \\
\hline P1 & $37(35.2)$ & $41(39.4)$ & \\
\hline P2 & $60(57.1)$ & $52(50.0)$ & \\
\hline P3 & $8(7.6)$ & $11(10.6)$ & \\
\hline \multicolumn{4}{|c|}{ Concomitant diseases ( $\geq 20 \%$ patients in either group), $n$ (\%) } \\
\hline Gastrointestinal, hepatic & $46(43.8)$ & $39(37.5)$ & 0.353 \\
\hline Cardiovascular & $31(29.5)$ & $35(33.7)$ & 0.521 \\
\hline Metabolic, endocrine, nutritional & $38(36.2)$ & $26(25.0)$ & 0.079 \\
\hline Allergic & $18(17.1)$ & $31(29.8)$ & 0.031 \\
\hline \multicolumn{4}{|c|}{ Concomitant medications ( $\geq 10 \%$ patients in either group), $\mathrm{n}(\%)$} \\
\hline Heparin & $51(48.6)$ & $47(45.2)$ & ND \\
\hline Combination of penicillins* & $17(16.2)$ & $9(8.7)$ & ND \\
\hline
\end{tabular}

*Including $\beta$-lactamase inhibitors.

ASA, American Society of Anesthesiologists; BMI, Body mass index; ND, Not determined.

was a single-blind study, the relationship to treatment could not be reported in the no adhesion barrier group. There was no relationship between the amount of HA/ CMC powder used and incidence of adverse events or serious adverse events (data not shown).

At least one SSI was experienced by 22/105 (21\%) of patients in the HA/CMC powder group versus 15/104 (14\%) in the no adhesion barrier group $(P=0.216)$, and at least one serious SSI by 13/105 (12\%) versus 9/104 (9\%), respectively $(P=0.38$; Table 5$)$. There were no numeric differences between the HA/CMC powder and the no adhesion barrier groups in the most frequently reported serious SSIs of pelvic abscess (4.8\% and 1.9\%, respectively), anastomotic fistula (2.9\% and $3.8 \%)$, and peritonitis (1.9\% and 2.9\%; statistical significance not tested).

In the HA/CMC powder group, the mean $\pm \mathrm{SD}$ amount of powder applied was $2.7 \pm 1.4 \mathrm{~g}$, with $40 \%$ of patients receiving 4 to $6 \mathrm{~g}$, 37\% receiving 2 to $3 \mathrm{~g}$, and $23 \%$ receiving only $1 \mathrm{~g}$. The mean \pm SD duration of application was $5.6 \pm 3.4 \mathrm{~min}$. The mean $\pm \mathrm{SD}$ duration of hospitalisation after surgery was $9.7 \pm 6.3$ days in the HA/CMC powder group compared with $7.5 \pm 3.4$ days in the no adhesion barrier group $(P=0.009)$.

Adverse events by preoperative diagnosis are summarized in Table 6. A greater frequency of adverse events among patients with cancer was observed than in patients with other diagnoses in both groups; however, the 
Table 2 Intra-operative parameters (intent-to-treat population)

\begin{tabular}{|c|c|c|}
\hline & $\begin{array}{c}\text { HA/CMC } \\
\text { powder }(n=105)\end{array}$ & $\begin{array}{c}\text { No adhesion } \\
\text { barrier }(n=104)\end{array}$ \\
\hline Adhesiolysis, n (\%) & $36(34.3)$ & $24(23.1)$ \\
\hline \multicolumn{3}{|l|}{ Type of resection, n (\%) } \\
\hline $\begin{array}{l}\text { Sigmoidectomy and/or } \\
\text { left colectomy }\end{array}$ & $44(41.9)$ & $50(48.1)$ \\
\hline Proctectomy & $21(20.0)$ & $25(24.0)$ \\
\hline Right ileocolectomy & $31(29.5)$ & $20(19.2)$ \\
\hline Total proctocolectomy & $5(4.8)$ & $3(2.9)$ \\
\hline $\begin{array}{l}\text { Abdominoperineal } \\
\text { amputation }\end{array}$ & $2(1.9)$ & $2(1.9)$ \\
\hline Total colectomy & $1(1.0)$ & $3(2.9)$ \\
\hline $\begin{array}{l}\text { Sigmoidectomy and right } \\
\text { ileocolectomy }\end{array}$ & 0 & $1(1.0)$ \\
\hline $\begin{array}{l}\text { Left colectomy and small } \\
\text { intestine resection (ileum) }\end{array}$ & $1(1.0)$ & 0 \\
\hline Anastomosis, n (\%) & $102(97.1)$ & $99(95.2)$ \\
\hline Manual & $28(27.5)^{*}$ & $15(15.2)$ \\
\hline Mechanical & $74(72.5)$ & $84(84.8)$ \\
\hline Stomy, n (\%) & $27(25.7)$ & $23(22.1)$ \\
\hline Partial omentectomy, n (\%) & $12(11.4)$ & $12(11.5)$ \\
\hline \multicolumn{3}{|l|}{$\begin{array}{l}\text { Classification of surgical area } \\
\text { during surgery, } \mathrm{n}(\%)\end{array}$} \\
\hline Clean - contaminated & $104(99.0)$ & $104(100)$ \\
\hline Contaminated & $1(1.0)$ & $0(0)$ \\
\hline Exeresis of other organs, n (\%) & $8(7.6)$ & $8(7.7)$ \\
\hline
\end{tabular}

${ }^{*} P=0.034$.

rate of overall adverse events and serious adverse events was higher in the HA/CMC powder group than in the no adhesion barrier group in patients with cancer $33 \%$ vs. $17 \%$ and $16 \%$ vs. $6 \%$, respectively; significance not tested). Similarly, adverse events were more frequent in the HA/CMC powder group versus the no adhesion barrier group in patients with Crohn's disease and ulcerative colitis (Table 6; significance not tested).

Subgroup analysis also indicated a greater frequency of adverse events among patients who had undergone previous abdominal/pelvic surgery than in those who had not in both groups; however, the rate of adverse events and serious adverse events was higher in the HA/CMC powder group than in the no adhesion barrier group, regardless of previous abdominal/pelvic surgery status (data not shown).

\section{Risk factor analysis}

For the serious adverse events risk factor analysis, the covariates included were age, smoking status, smoking frequency, use of corticoids, surgical risk (National Nosocomial Infections Surveillance Index; NNIS), previous
Table 3 Summary of perioperative parameters

\begin{tabular}{|c|c|c|}
\hline & $\begin{array}{c}\text { HA/CMC } \\
\text { powder }(n=105)\end{array}$ & $\begin{array}{c}\text { No adhesion } \\
\text { barrier }(n=104)\end{array}$ \\
\hline $\begin{array}{l}\text { Estimated blood loss in } \mathrm{mL}, \\
\text { mean } \pm \mathrm{SD}\end{array}$ & $116.5 \pm 197.7$ & $81.6 \pm 95.8$ \\
\hline $\begin{array}{l}\text { Administration of blood } \\
\text { products, } \mathrm{n}(\%)\end{array}$ & $7(6.7)$ & $3(2.9)$ \\
\hline $\begin{array}{l}\text { Blood sediments in units, } \\
\text { mean } \pm S D\end{array}$ & $2.0 \pm 1.0$ & $1.7 \pm 0.6$ \\
\hline Perioperative lavage, n (\%) & $73(69.5)$ & $73(70.2)$ \\
\hline Intraperitoneal & $58(79.5)$ & $54(74.0)$ \\
\hline Intraluminal & $4(5.5)$ & $2(2.7)$ \\
\hline $\begin{array}{l}\text { Intraperitoneal and } \\
\text { intraluminal }\end{array}$ & $11(15.1)$ & $17(23.3)$ \\
\hline \multicolumn{3}{|l|}{$\begin{array}{l}\text { Type of intraperitoneal lavage, } \\
\mathrm{n}(\%)\end{array}$} \\
\hline Localized to intervention site & $52(76.5)$ & $54(77.1)$ \\
\hline Whole cavity & $16(23.5)$ & $16(22.9)$ \\
\hline $\begin{array}{l}\text { Use of povidone-iodine } \\
\text { antiseptic irrigation, } \mathrm{n}(\%)\end{array}$ & 19 (18.6) & $23(22.8)$ \\
\hline Intraperitoneal & $4(21.1)$ & $5(21.7)$ \\
\hline Intraluminal & $12(63.2)$ & $14(60.9)$ \\
\hline $\begin{array}{l}\text { Intraperitoneal and } \\
\text { intraluminal }\end{array}$ & $3(15.8)$ & $4(17.4)$ \\
\hline Drain, n (\%) & $50(47.6)$ & $49(47.1)$ \\
\hline Vacuum, n (\%) & $37(74.0)$ & $37(75.5)$ \\
\hline Number of drains, mean \pm SD & $1.1 \pm 0.3^{*}$ & $1.6 \pm 1.5$ \\
\hline $\begin{array}{l}\text { Surgery duration in minutes, } \\
\text { mean } \pm S D\end{array}$ & $216.2 \pm 87.1$ & $203.2 \pm 81.6$ \\
\hline $\begin{array}{l}\text { Postoperative oxygen therapy, } \\
\text { n (\%) }\end{array}$ & $69(65.7)$ & $56(53.8)$ \\
\hline
\end{tabular}

cancer, fluorouracil used during the most recent chemotherapy and abdominal or pelvic radiation therapy administration. The probability of a serious adverse event was greater in the HA/CMC powder versus the no adhesion barrier group (OR $=4.08 ; 95 \% \mathrm{CI}, 1.67-9.95 ; P=0.002$ ), in younger patients (for age in years, $\mathrm{OR}=0.94 ; 95 \% \mathrm{CI}$, $0.91-0.98 ; P=0.002)$, and in patients who smoked frequently $(\mathrm{OR}=1.06 ; 95 \% \mathrm{CI}, 1.02-1.10 ; P=0.006)$. The probability of a serious adverse event was also greater in patients with a higher level of surgical risk: NNIS index 0 vs. -1 (OR $=1.33 ; 95 \% \mathrm{CI}, 0.53-3.36 ; P=0.027)$ and NNIS index 1 vs. $-1(\mathrm{OR}=9.87 ; 95 \% \mathrm{CI}, 1.82-53.53 ; P=0.027)$, in those with previous cancer $(\mathrm{OR}=3.46$; $95 \% \mathrm{CI}, 1.02-$ 11.70; $P=0.046)$ and in those having used fluorouracil during their last chemotherapy $(\mathrm{OR}=7.12$; $95 \% \mathrm{CI}, 1.52$ 33.42; $P=0.013$ ).

For the deep SSIs risk factor analysis, age and smoking frequency were included as covariates. The probability for a deep SSI was greater in younger patients (for age in years $\mathrm{OR}=0.97 ; 95 \% \mathrm{CI}, 0.94-1.00 ; P=0.0362)$ and 
Table 4 Summary of deaths, adverse events, and serious adverse events (events occurring on or after the day of surgery are shown by preferred term)

\begin{tabular}{|c|c|c|}
\hline & $\begin{array}{c}\text { HA/CMC powder } \\
(n=105)\end{array}$ & $\begin{array}{c}\text { No adhesion } \\
\text { barrier }(n=104)\end{array}$ \\
\hline Deaths & $1(1.0)$ & $1(1.0)$ \\
\hline Any adverse event*, n (\%) & $66(62.9)^{\dagger}$ & $41(39.4)$ \\
\hline $\begin{array}{l}\text { Any adverse event } \\
\text { considered severe, } \mathrm{n}(\%)^{\S}\end{array}$ & $14(13.3)$ & $5(4.8)$ \\
\hline \multicolumn{3}{|l|}{$\begin{array}{l}\text { Most frequently reported } \\
\text { adverse events, } \mathrm{n}(\%)^{\mathrm{s}}\end{array}$} \\
\hline Hyperthermia & $6(5.7)$ & $3(2.9)$ \\
\hline Incision site abscess & $5(4.8)$ & $3(2.9)$ \\
\hline Pelvic abscess & $5(4.8)$ & $2(1.9)$ \\
\hline Urinary tract infection & $5(4.8)$ & $1(1.0)$ \\
\hline Anastomotic fistula & $4(3.8)$ & $4(3.8)$ \\
\hline Abdominal wall abscess & $4(3.8)$ & $2(1.9)$ \\
\hline lleus & $3(2.9)$ & $2(1.9)$ \\
\hline Urinary retention & $3(2.9)$ & $1(1.0)$ \\
\hline $\begin{array}{l}\text { At least } 1 \text { serious adverse event, } \\
\mathrm{n}(\%)\end{array}$ & $29(27.6)^{\dagger}$ & $11(10.6)$ \\
\hline $\begin{array}{l}\text { Any serious adverse event } \\
\text { considered severe, } \mathrm{n}(\%)^{\S}\end{array}$ & $9(8.6)$ & $3(2.9)$ \\
\hline \multicolumn{3}{|l|}{$\begin{array}{l}\text { Serious adverse events } \\
\text { occurring in } \geq 2 \text { patients in } \\
\text { either group, } \mathrm{n}(\%)^{\S}\end{array}$} \\
\hline Pelvic abscess & $5(4.8)$ & $2(1.9)$ \\
\hline $\begin{array}{l}\text { Abdominal } \\
\text { abscess }\end{array}$ & $4(3.8)$ & 0 \\
\hline Septic shock & $1(1.0)$ & $2(1.9)$ \\
\hline Peritonitis & $2(1.9)$ & $3(2.9)$ \\
\hline lleus & $3(2.9)$ & 0 \\
\hline Anastomotic fistula & $3(2.9)$ & $4(3.8)$ \\
\hline $\begin{array}{l}\text { Gastrointestinal stoma } \\
\text { complication }\end{array}$ & $2(1.9)$ & 0 \\
\hline
\end{tabular}

*All adverse events coded according to the Medical Dictionary for Regulatory Activities version 11.0.

${ }^{\dagger} P<0.001$ vs. no adhesion barrier group.

${ }^{5}$ Statistical significance not tested.

in patients who frequently smoked $(\mathrm{OR}=1.05 ; 95 \% \mathrm{CI}$, 1.01-1.09; $P=0.010)$. No significant effect of treatment was observed $(\mathrm{OR}=0.58 ; 95 \% \mathrm{CI}, 0.22-1.53 ; P=0.269)$.

\section{Ease of use and reliability}

$\mathrm{HA} / \mathrm{CMC}$ powder was considered to be manageable by nurses in $98 \%(103 / 105)$ of procedures, based on ease of use assessment (Figure 2A). Surgeons considered $\mathrm{HA} / \mathrm{CMC}$ powder manageable and reliable in $94 \%$ (99/ $105)$ and $79 \%(83 / 105)$ of procedures, respectively (Figure 2A,B).
Table 5 Overall frequency of SSIs and serious SSIs, and listing of all SSIs

\begin{tabular}{lccc}
\hline & $\begin{array}{c}\text { HA/CMC powder } \\
(\mathbf{n}=105)\end{array}$ & $\begin{array}{c}\text { No adhesion } \\
\text { barrier } \\
(\mathbf{n}=104)\end{array}$ & $P$ value \\
\hline At least 1 SSI, n (\%) & $22(21.0)$ & $15(14.4)$ & 0.216 \\
$\quad 13(12.4)$ & $8(7.7)$ & 0.260 \\
$\quad$ Deep & $13(12.4)$ & $7(6.7)$ & 0.165 \\
$\quad$ Incisional & $13(12.4)$ & $9(8.7)$ & 0.380 \\
At least 1 serious SSI, & & & \\
n (\%) & $12(11.4)$ & $8(7.7)$ & 0.359 \\
$\quad$ Deep & $2(1.9)$ & $1(1.0)$ & 1.000
\end{tabular}

All SSIs, n (\%)

\begin{tabular}{|c|c|c|c|}
\hline $\begin{array}{l}\text { Infections and } \\
\text { infestations }\end{array}$ & $20(19.0)$ & $11(10.6)$ & - \\
\hline $\begin{array}{l}\text { Incision site } \\
\text { abscess }\end{array}$ & $5(4.8)$ & $3(2.9)$ & - \\
\hline Pelvic abscess & $5(4.8)$ & $2(1.9)$ & - \\
\hline $\begin{array}{l}\text { Abdominal wall } \\
\text { abscess }\end{array}$ & $4(3.8)$ & $2(1.9)$ & - \\
\hline Abdominal abscess & $4(3.8)$ & 0 & - \\
\hline $\begin{array}{l}\text { Incision site } \\
\text { infection }\end{array}$ & $1(1.0)$ & $2(1.9)$ & - \\
\hline Abscess intestinal & $1(1.0)$ & $1(1.0)$ & - \\
\hline $\begin{array}{l}\text { Abdominal } \\
\text { infection }\end{array}$ & $1(1.0)$ & 0 & - \\
\hline Bacteraemia & $1(1.0)$ & 0 & - \\
\hline $\begin{array}{l}\text { Postoperative } \\
\text { abscess }\end{array}$ & $1(1.0)$ & 0 & - \\
\hline Septic shock & 0 & $1(1.0)$ & - \\
\hline $\begin{array}{l}\text { Subcutaneous } \\
\text { abscess }\end{array}$ & $1(1.0)$ & 0 & - \\
\hline $\begin{array}{l}\text { Injury, poisoning, } \\
\text { and procedural } \\
\text { complications }\end{array}$ & $6(5.7)$ & $4(3.8)$ & - \\
\hline Anastomotic fistula & $4(3.8)$ & $4(3.8)$ & - \\
\hline $\begin{array}{l}\text { Gastrointestinal } \\
\text { anastomotic leak }\end{array}$ & $1(1.0)$ & 0 & - \\
\hline $\begin{array}{l}\text { Incision site } \\
\text { complication }\end{array}$ & $1(1.0)$ & 0 & - \\
\hline $\begin{array}{l}\text { Gastrointestinal } \\
\text { disorders }\end{array}$ & $2(1.9)$ & $5(4.8)$ & - \\
\hline Peritonitis & $2(1.9)$ & $3(2.9)$ & - \\
\hline Colonic fistula & 0 & $1(1.0)$ & - \\
\hline $\begin{array}{l}\text { Gastrointestinal } \\
\text { inflammation }\end{array}$ & 0 & $1(1.0)$ & - \\
\hline
\end{tabular}

Shown by system organ class and preferred term.

-, Statistical significance not tested.

SSI, Surgical site infection.

\section{Discussion}

In this exploratory study evaluating safety outcomes, there were statistically significant differences between the HA/CMC powder and the no adhesion barrier 
Table 6 Frequency of adverse events, serious adverse events, and serious SSIs by preoperative diagnosis

\begin{tabular}{|c|c|c|}
\hline Preoperative diagnosis & $\begin{array}{c}\text { HA/CMC } \\
\text { powder }(n=105)\end{array}$ & $\begin{array}{c}\text { No adhesion } \\
\text { barrier }(n=104)\end{array}$ \\
\hline \multicolumn{3}{|l|}{ Cancer, n (\%) } \\
\hline Adverse event & $35(33.3)$ & $18(17.3)$ \\
\hline Serious adverse event & $17(16.2)$ & $6(5.8)$ \\
\hline Serious SSI & $4(3.8)$ & $5(4.8)$ \\
\hline \multicolumn{3}{|l|}{ Diverticulosis, n (\%) } \\
\hline Adverse event & $11(10.5)$ & $12(11.5)$ \\
\hline Serious adverse event & $2(1.9)$ & $2(1.9)$ \\
\hline Serious SSI & $2(1.9)$ & $2(1.9)$ \\
\hline \multicolumn{3}{|l|}{ Crohn's disease, n (\%) } \\
\hline Adverse event & $7(6.7)$ & $2(1.9)$ \\
\hline Serious adverse event & $4(3.8)$ & $1(1.0)$ \\
\hline Serious SSI & $4(3.8)$ & $1(1.0)$ \\
\hline \multicolumn{3}{|l|}{ Ulcerative colitis, n (\%) } \\
\hline Adverse event & $5(4.8)$ & $4(3.8)$ \\
\hline Serious adverse event & $3(2.9)$ & $1(1.0)$ \\
\hline Serious SSI & $2(1.9)$ & 0 \\
\hline \multicolumn{3}{|l|}{ Polyp (no cancer), n (\%) } \\
\hline Adverse event & $4(3.8)$ & $4(3.8)$ \\
\hline Serious adverse event & $1(1.0)$ & $1(1.0)$ \\
\hline Serious SSI & 0 & 0 \\
\hline \multicolumn{3}{|l|}{ Endometriosis } \\
\hline Adverse event & $1(1.0)$ & $1(1.0)$ \\
\hline Serious adverse event & $1(1.0)$ & 0 \\
\hline Serious SSI & $1(1.0)$ & 0 \\
\hline \multicolumn{3}{|l|}{ Polyposis } \\
\hline Adverse event & $1(1.0)$ & 0 \\
\hline Serious adverse event & 0 & 0 \\
\hline Serious SSI & 0 & $1(1.0)$ \\
\hline \multicolumn{3}{|l|}{ Other } \\
\hline Adverse event & $2(1.9)$ & 0 \\
\hline Serious adverse event & $1(1.0)$ & 0 \\
\hline Serious SSI & 0 & 0 \\
\hline
\end{tabular}

SSI, Surgical site infection.

groups in the frequency of adverse events and serious adverse events $(P<0.001)$. The occurrence of abdominopelvic abscess was more frequent in the HA/CMC powder group than in the no adhesion barrier group, although there were no statistically significant differences between groups in the frequency of SSIs or serious SSIs. Surgeons considered HA/CMC powder easy to use and reliable, and nurses also considered HA/CMC powder to be manageable in the majority of procedures. Based on the observed safety findings, the use of HA/CMC powder is no longer being pursued in colorectal laparoscopic surgery.

The most frequent types of adverse events were those often encountered in patients undergoing colorectal or intestinal resection ('infections and infestations' and 'gastro-intestinal disorders'). Among the adverse events and serious adverse events that were considered by investigators to be related to treatment, there was not one particular type of event or safety issue that was more frequently reported than others. Frequency appeared to be independent of the quantity of HA/CMC powder applied. There was a trend towards a higher frequency of adverse events in patients with cancer versus other aetiologies, and a higher frequency of adverse events in the HA/CMC powder group versus the no adhesion barrier group in patients with cancer and those with inflammatory pathologies, although the study was not powered to detect a significant difference for such a subgroup analysis. As this was an exploratory study, no sample size calculation was made, but the enrolment of approximately 100 patients per group would have provided a 95\% CI of 25.6 to 44.4 for the detected difference, based on an expected overall rate of serious adverse events of $35 \%[21]$.

Other studies report that SSIs occur following colorectal surgery with a frequency ranging from $5 \%$ to $45 \%$ [25-33]; the frequency of SSIs observed in this study falls within this range. The risk factor analysis in our study found no significant effect of treatment on risk for deep SSIs. Factors that appeared to be associated with a greater risk were lower age and frequent smoking. There was a significant treatment effect on risk of serious adverse events; other factors that appeared to be associated with a greater risk were lower age, frequent smoking, high level of surgical risk, previous cancer, and having used fluorouracil during the last chemotherapy. However, given the exploratory design of this study, these results must be considered with caution.

The findings of our study were unexpected given that no safety issues were identified in a pilot study by Fossum et al. assessing the use of HA/CMC powder in laparoscopic myomectomy [20]. In their study, Fossum et al. observed no overall difference in adverse event frequency between the HA/CMC powder and the no adhesion barrier groups ( $67 \%$ vs. $60 \%$, respectively), and only one patient experienced a serious adverse event (leukaemia, in the no adhesion barrier group). No adverse events directly related to $\mathrm{HA} / \mathrm{CMC}$ powder were identified, as determined by the surgeon, and there were no reports of SSIs or intra-abdominal abscess. Furthermore, in animal models, HA/CMC powder has been shown to be effective in preventing adhesions without affecting wound healing $[18,19]$. In a rat model of anastomotic healing, there were no statistically significant differences between the HA/ 


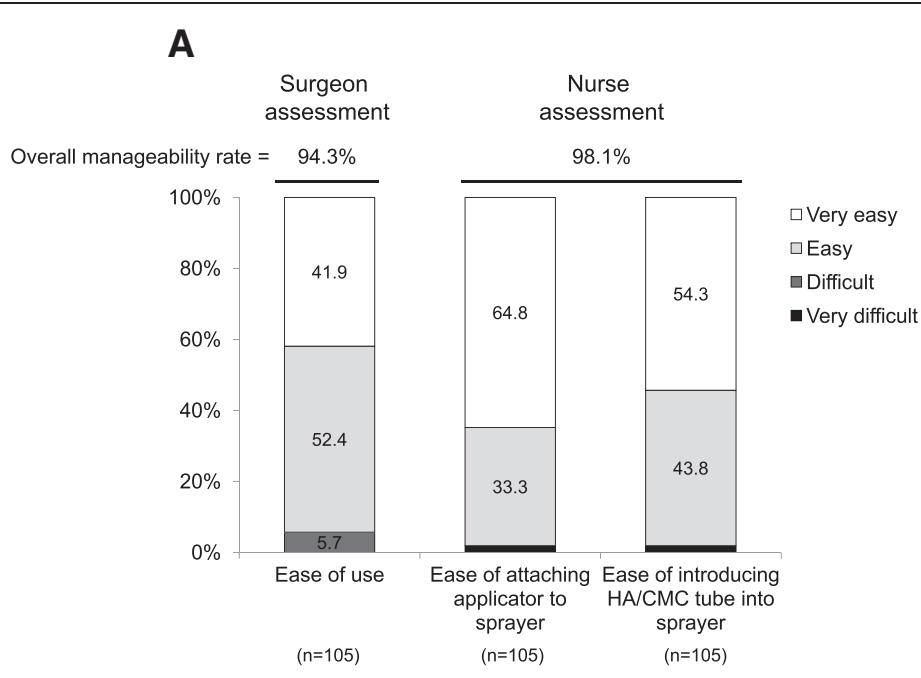

B

Overall reliability rate $=79.0 \%$

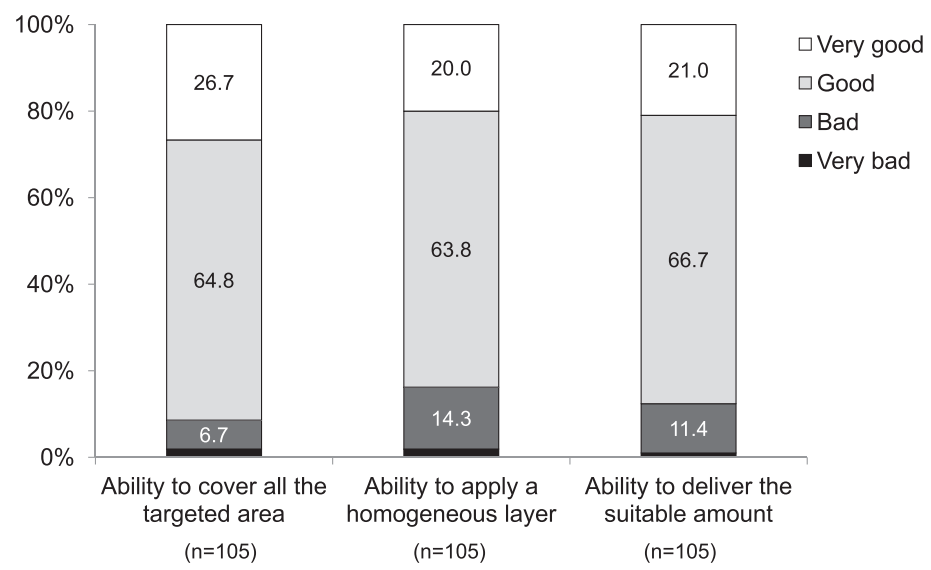

Figure 2 Ease of use and reliability. (A) Ease of use of HA/CMC powder, as assessed by surgeons and nurses; (B) Reliability of HA/CMC powder, as assessed by surgeons. Overall manageability/reliability rates determined by overall number of cases scoring 3 or 4 on a 4-point scale ( 3 = easy or good, 4 = very easy or very good). For multi-component items, all were required to achieve a score of 3 or 4.

CMC powder and the no adhesion barrier groups in number of deaths or short-term complications of abscess formation, bowel obstruction, proximal colonic dilatation, and wound dehiscence [19].

In the present study, an important consideration was that the patient population enrolled had a high level of comorbidity and a high probability of postoperative morbidity. This population was intended to be heterogeneous, comprising a broad range of patients undergoing various abdominal surgeries for a variety of diagnoses, including cancer. The risk of postoperative infection is high in patients undergoing gastrointestinal surgery as a result of opening the bowel, whereas gynaecologic surgery is usually a 'clean' (Class I) wound in comparison [34]. Although direct comparison with other studies is not possible, the overall rate of adverse events in the no adhesion barrier group in this study (39\%) was similar to overall postoperative comorbidity rates in prospective studies of open or laparoscopic colorectal surgery ( 25\% to $35 \%)[21,35]$. However, this does not explain the significantly higher frequency of adverse events and serious adverse events in the $\mathrm{HA} / \mathrm{CMC}$ powder group versus the no adhesion barrier group. Intraoperative and perioperative parameters that differed between groups were adhesiolysis and manual anastomosis (both performed more frequently in the HA/CMC powder group), number of drains (lower in the HA/CMC powder group), and mean duration of surgery (longer in the HA/CMC powder group).

As the safety of the film formulation has been confirmed in clinical studies of gynaecological and abdominal surgery $[13,14,36,37]$, the powder formulation of HA/CMC used in this study is likely to be an important contributing factor for the increased frequency of adverse events and 
serious adverse events. One study noted that wrapping a new bowel anastomosis with HA/CMC film adhesion barrier increased the risk of anastomotic leak and related events such as fistula, peritonitis, abscess, and sepsis [24], possibly by interfering with anastomosis healing; this practice is therefore contraindicated. For adhesion barriers with a liquid or gel formulation, greater diffusion of product across the peritoneal surface may play a role in increasing adverse event risk as a result of application occurring away from the wound site. Gels may also have a propensity to pool away from the wound site. A study of $0.5 \%$ ferric hyaluronate gel adhesion barrier in open colorectal surgery was suspended owing to significantly greater morbidity versus the control group (distilled water, $65 \%$ vs. $27 \% ; P=0.031$ ). There was a higher rate of anastomotic dehiscence (5/17 vs. $1 / 15$, respectively; not significant) [34] but investigators were unable to determine whether anastomotic healing was disrupted directly by the adhesion barrier or by infection associated with gel use. Furthermore, icodextrin $4 \%$ fluid is indicated for use only in patients undergoing gynaecological laparoscopic adhesiolysis in the USA owing to occurrence of serious complications following laparotomy and bowel resection/repair [38]. Pre-clinical data suggested that HA/CMC powder demonstrated more rapid dissolution and wider diffusion than HA/CMC film [19], with a greater capacity for fluid absorption and release of a higher concentration of polymer into solution within the first few hours of hydration than the equivalent amount of HA/CMC film [18]. As application of $\mathrm{HA} / \mathrm{CMC}$ film to anastomoses is contraindicated owing to the potential for an increase in anastomotic leak-related events [24], great care was taken in our study to practise avoidance of anastomoses with HA/CMC powder. Nevertheless, due to the potential for greater diffusion of the powder formulation, the authors speculate that migration away from the application site to anastomoses could have occurred in some cases. Furthermore, over-hydration of the HA/CMC powder might have resulted in pooling of the resulting gel away from the application site, raising the possibility of migration onto an anastomosis or provision of a nidus for abscess; such migration to anastomoses might increase the rate of SSIs.

There is no current evidence of a biological effect of $\mathrm{HA} / \mathrm{CMC}$ [39-41], although hyaluronan is known to promote cell proliferation and migration [42]. Histological analysis of tissues from pre-clinical studies indicated that macrophage response and rate of remesothelialisation appeared to be similar for both film and powder formulations [18]. There may be potential for powder and gel formulations to act as sites of origin for abscess formation, and/or to be associated with septic complications [19]. An animal study assessing the effect of adhesion barriers on the progression of bacterial infection in the peritoneum found that HA/CMC films had no effect when compared with control groups (saline), whereas some modified gel formulations appeared to increase mortality [43]. Furthermore, testing of $\mathrm{HA} / \mathrm{CMC}$ powder in a rat model of sepsis involving simultaneous exposure to variable doses of Escherichia coli and sterile caecal contents identified a safety signal on repeat testing (unpublished data, Genzyme Biosurgery), suggesting adverse effects in the presence of active infection or gross caecal contamination. Pre-clinical studies observed an infection potentiation resulting from a physical interaction of $\mathrm{HA} / \mathrm{CMC}$ powder with caecal material and bacteria during the initial stages of hydration within the first $4 \mathrm{~h}$ of implantation (unpublished data, Genzyme Biosurgery). Although our study excluded patients with pathology requiring class IV contamination surgery and those with abdominal abscesses and/or peritonitis or abdominal cavity infection, it is possible that in some patients the presence of HA/CMC powder in combination with luminal contents resulted in adverse events owing to peritoneal bacterial contamination.

The main limitation of this trial is its exploratory nature and lack of efficacy assessment. The study population enrolled was a heterogeneous and difficult-to-treat population with a high risk of morbidity and a broad range of aetiologies; therefore, these results cannot be extrapolated to other patient populations. The key strength of the study was the care taken to standardize the application technique according to the instructions provided. The findings suggest that the observed safety signals are most likely related to the specific formulation (powder); therefore, these results should not be extrapolated to other formulations of adhesion barriers.

\section{Conclusions}

This exploratory study found significantly higher rates of adverse events and serious adverse events in the HA/CMC powder group compared with the no adhesion barrier group, indicating a global safety signal in the laparoscopic application of $\mathrm{HA} / \mathrm{CMC}$ powder in colorectal and small bowel resection. Thus, further development of HA/CMC powder is no longer being pursued for use in patients undergoing colorectal and small bowel laparoscopic surgery, given that this population has an elevated risk for postoperative comorbidity.

\section{Abbreviations}

Cl: Confidence interval; HA/CMC: Hyaluronic acid/carboxymethylcellulose NNIS: National Nosocomial Infections Surveillance Index; OR: Odds ratio; SSIs: Surgical site infections.

\section{Competing interests}

This study was sponsored by Sanofi (formerly Genzyme Corporation), Cambridge, MA, USA. All study sites received compensation in support of patient enrolment and principal investigators were reimbursed for travel and accommodation expenses related to investigator meetings by the study sponsor. The article processing charge was paid by the study sponsor. SVB received fees from Genzyme/Sanofi as a member of the steering committee of the present trial and received reimbursement from Genzyme/Sanofi 
for attending the $8^{\text {th }}$ Congrès Francophone de Chirurgie Digestive et Hépato-Biliaire (SFCD-ACHBT), 28-30 November 2012, Paris. CM received fees from Genzyme/Sanofi as a member of the steering committee of the present trial and a further European trial, received an educational grant from Genzyme/Sanofi for providing an anti-adhesion barriers literature review, and received speaker fees from Genzyme/Sanofi relating to the $8^{\text {th }}$ Congrès Francophone de Chirurgie Digestive et Hépato-Biliaire (SFCD-ACHBT), 28-30 November 2012, Paris and the $114^{\text {th }}$ Congress of the Association Française de Chirurgie, 3-5 October 2012, Paris. CD, YP, CL, EC, and NH have no additional interests to disclose. ELPF is an employee of Sanofi (formerly Genzyme Corporation). J-JD received funding from Sanofi (formerly Genzyme Corporation) in 2009 in relation to a previous study.

\section{Authors' contributions}

SVB acted as study co-ordinator and principal investigator, participated in the design of the study, was involved as a study steering committee member, enrolled patients and collected data, was involved in the analysis and interpretation of the data, and drafted the manuscript. CM participated in the design of the study, was involved as a study steering committee member and in the analysis and interpretation of the data and critical revision of the manuscript. CD, CL, and EC enrolled patients and collected data, were involved in the interpretation of the data and critical revision of the manuscript. YP and $\mathrm{NH}$ acted as principal investigators, enrolled patients and collected data, and were involved in the interpretation of the data and critical revision of the manuscript. ELPF acted as the medical project manager, participated in the design of the study, and was involved in the analysis and interpretation of the data and critical revision of the manuscript. J-JD participated in the design of the study, was involved as a study steering committee member, was involved in the analysis and interpretation of the data, and drafted the manuscript. All authors read and approved the final manuscript.

\section{Acknowledgements}

The authors acknowledge the contributions to this study of the following co-investigators: Pr Michel Scotté, Hôpital Charles Nicolle, Rouen; Dr Hugues Levard, Institut Mutualiste Montsouris, Paris; Pr Jean Gugenheim, Hôpital de I'Archet, Nice; Pr Olivier Glehen, Centre Hospitalier Lyon-Sud, Pierre-Bénite; Dr Guillaume Meurette and Pr Paul-Antoine Lehur, Hôpital Hôtel-Dieu, Nantes; Dr Alexandre Rault, Hôpital Haut-Lévêque, Bordeaux; Dr Mohamed Saïd Sbaï Idrissi, Centre Hospitalier Simone Veil, Eaubonne; Pr Philippe Wind, Hôpital Avicenne, Bobigny; Dr Elie Chouillard, Centre Hospitalier Intercommunal de Poissy-Saint Germain en Laye, Poissy (acting on behalf of iNOELS - the Intercontinental Society of Natural Orifice, Endoscopic, and Laparoscopic Surgery); and Pr Pierre Verhaeghe, Hôpital Amiens Nord, Amiens. The authors also acknowledge Dr Sylvie Marlier-Bonnot, Sanofi, Saint-Germain en Laye, France for her role in overseeing the study. Mrudula Donepudi PhD, Sanofi, Cambridge, MA, USA, provided constructive input during manuscript development. Editorial/writing support for the preparation of this manuscript was provided by Helen Varley PhD CMPP, Envision Custom Solutions, Horsham, UK, funded by Sanofi. The authors, however, were fully responsible for all content and editorial decisions and received no financial support or other form of compensation related to the development of the paper. This study (NCT00813397) was funded by Sanofi (formerly Genzyme Corporation), Cambridge, MA, USA.

\section{Author details}

${ }^{1}$ Chirurgie Digestive, Hôpital Nord, CERC (Centre d'Enseignement et de Recherche Chirurgical), Aix-Marseille Université, Chemin des Bourrellys, 13915 Marseille, Cedex 20, France. ${ }^{2}$ Chirurgie Digestive et Générale, Hôpital Claude Huriez, Centre Hospitalier Régional Universitaire, 2 Avenue Oscar Lambret, 59037 Lille, Cedex, France. Institut Mutualiste Montsouris, 42 Boulevard Jourdan, 75674 Paris, Cedex 14, France. ${ }^{4}$ Chirurgie Colorectale, Hôpital Beaujon, 100 Boulevard du Général Leclerc, 92110 Clichy, France. ${ }^{5}$ Chirurgie Générale et Digestive, Hôpital Saint André, 1 Rue Jean Burguet, 33000 Bordeaux, France. ${ }^{6}$ Chirurgie Digestive et Endocrinienne, Centre Hospitalier Lyon-Sud, Chemin du Grand Revoyet, 69310 Pierre-Bénite, France. ${ }^{7}$ Centre Hospitalier Régional Universitaire de Tours, Avenue de la République, 37170 Chambray-lès-Tours, France. ${ }^{8}$ Sanofi (Genzyme), 33-35 Boulevard de la Paix, 78105 Saint-Germain-en-Laye, Cedex, France. ${ }^{9}$ Chirurgie Générale et Digestive, Hôpital Pitié Salpêtrière, 47-83 Boulevard de l'Hôpital, 75013 Paris, France.
Received: 30 April 2014 Accepted: 8 October 2014

Published: 27 October 2014

\section{References}

1. Ouaïssi M, Gaujoux S, Veyrie N, Denève E, Brigand C, Castel B, Duron JJ, Rault A, Slim K, Nocca D: Post-operative adhesions after digestive surgery: their incidence and prevention: review of the literature. J Visc Surg 2012, 149:e104-114.

2. Diamond MP, Wexner SD, DiZereg GS, Korell M, Zmora O, Van Goor H, Kamar M: Adhesion prevention and reduction: current status and future recommendations of a multinational interdisciplinary consensus conference. Surg Innov 2010, 17:183-188.

3. Miller G, Boman J, Shrier I, Gordon PH: Etiology of small bowel obstruction. Am J Surg 2000, 180:33-36.

4. Duron JJ, Hay JM, Msika S, Gaschard D, Domergue J, Gainant A, Fingerhut A: Prevalence and mechanisms of small intestinal obstruction following laparoscopic abdominal surgery: a retrospective multicenter study. French Association for Surgical Research. Arch Surg 2000, 135:208-212.

5. O'Connor DB, Winter DC: The role of laparoscopy in the management of acute small-bowel obstruction: a review of over 2,000 cases. Surg Endosc 2012, 26:12-17.

6. Ten Broek RP, Issa Y, Van Santbrink EJ, Bouvy ND, Kruitwagen RF, Jeekel J, Bakkum EA, Rovers MM, Van Goor H: Burden of adhesions in abdominal and pelvic surgery: systematic review and met-analysis. BMJ 2013, 347:f5588.

7. Coleman MG, McLain AD, Moran BJ: Impact of previous surgery on time taken for incision and division of adhesions during laparotomy. Dis Colon Rectum 2000, 43:1297-1299.

8. Van Der Krabben AA, Dijkstra FR, Nieuwenhuijzen M, Reijnen MM, Schaapveld M, Van Goor H: Morbidity and mortality of inadvertent enterotomy during adhesiotomy. Br J Surg 2000, 87:467-471

9. Di Saverio S, Coccolini F, Galati M, Smerieri N, Biffl WL, Ansaloni L, Tugnoli G, Velmahos GC, Sartelli M, Bendinelli C, Fraga GP, Kelly MD, Moore FA, Mandala V, Mandala S, Masetti M, Jovine E, Pinna AD, Peitzman AB, Leppaniemi A, Sugarbaker PH, Van Goor H, Moore EE, Jeekel J, Catena F: Bologna guidelines for diagnosis and management of adhesive small bowel obstruction (ASBO): 2013 update of the evidence-based guidelines from the world society of emergency surgery ASBO working group. World J Emerg Surg 2013, 8:42.

10. Ten Broek RP, Kok-Krant N, Bakkum EA, Bleichrodt RP, Van Goor H: Different surgical techniques to reduce post-operative adhesion formation: a systematic review and meta-analysis. Hum Reprod Update 2013, 19:12-25.

11. Dowson HM, Bong JJ, Lovell DP, Worthington TR, Karanjia ND, Rockall TA: Reduced adhesion formation following laparoscopic versus open colorectal surgery. Br J Surg 2008, 95:909-914.

12. Polymeneas G, Theodosopoulos T, Stamatiadis A, Kourias E: A comparative study of postoperative adhesion formation after laparoscopic vs open cholecystectomy. Surg Endosc 2001, 15:41-43.

13. Ten Broek RP, Stommel MW, Strik C, Van Laarhoven CJ, Keus F, Van Goor H: Benefits and harms of adhesion barriers for abdominal surgery: a systematic review and meta-analysis. Lancet 2014, 383:48-59.

14. Becker JM, Dayton MT, Fazio WW, Beck DE, Stryker SJ, Wexner SD, Wolff BG, Roberts PL, Smith LE, Sweeney SA, Moore M: Prevention of postoperative abdominal adhesions by a sodium hyaluronate-based bioresorbable membrane: a prospective, randomized, double-blind multicenter study. J Am Coll Surg 1996, 183:297-306.

15. Vrijland WW, Tseng LN, Eijkman HJ, Hop WC, Jakimowicz JJ, Leguit P, Stassen $L P$, Swank DJ, Haverlag R, Bonjer HJ, Jeekel H: Fewer intraperitoneal adhesions with use of hyaluronic acid-carboxymethylcellulose membrane: a randomized clinical trial. Ann Surg 2002, 235:193-199.

16. Hashimoto D, Hirota M, Yagi Y, Baba H: Hyaluronate carboxymethylcellulosebased bioresorbable membrane (Seprafilm) reduces adhesion under the incision to make unplanned re-laparotomy safer. Surg Today 2012, 42:863-867.

17. Fazio WW, Cohen Z, Fleshman JW, Van Goor H, Bauer JJ, Wolff BG, Corman M, Beart RW Jr, Wexner SD, Becker JM, Monson JR, Kaufman HS, Beck DE, Bailey HR, Ludwig KA, Stamos MJ, Darzi A, Bleday R, Dorazio R, Madoff RD, Smith LE, Gearhart S, Lillemoe K, Gohl J: Reduction in adhesive smallbowel obstruction by Seprafilm adhesion barrier after intestinal resection. Dis Colon Rectum 2006, 49:1-11. 
18. Greenawalt KE, Colt MJ, Corazzini RL, Syrkina OL, Jozefiak TH: Remote efficacy for two different forms of hyaluronate-based adhesion barriers. J Invest Surg 2012, 25:174-180.

19. Sheldon HK, Gainsbury ML, Cassidy MR, Chu DI, Stucchi AF, Becker JM: A sprayable hyaluronate/carboxymethylcellulose adhesion barrier exhibits regional adhesion reduction efficacy and does not impair intestinal healing. J Gastrointest Surg 2012, 16:325-333.

20. Fossum GT, Silverberg KM, Miller CE, Diamond MP, Holmdahl L: Gynecologic use of Sepraspray Adhesion Barrier for reduction of adhesion development after laparoscopic myomectomy: a pilot study. Fertil Steril 2011, 96:487-491.

21. Alves A, Panis Y, Mathieu P, Mantion G, Kwiatkowski F, Slim K: Postoperative mortality and morbidity in French patients undergoing colorectal surgery: results of a prospective multicenter study. Arch Surg 2005, 140:278-283. Discussion 284

22. Mangram AJ, Horan TC, Pearson ML, Silver LC, Jarvis WR: Guideline for prevention of surgical site infection, 1999. Hospital Infection Control Practices Advisory Committee. Infect Control Hosp Epidemiol 1999, 20:250-278. Quiz 279-280.

23. Burns JW, Colt MJ, Burgees LS, Skinner KC: Preclinical evaluation of Seprafilm bioresorbable membrane. Eur J Surg Supp/ 1997, 577:40-48.

24. Beck DE, Cohen Z, Fleshman JW, Kaufman HS, Van Goor H, Wolff BG: A prospective, randomized, multicenter, controlled study of the safety of Seprafilm adhesion barrier in abdominopelvic surgery of the intestine. Dis Colon Rectum 2003, 46:1310-1319.

25. Romy S, Eisenring MC, Bettschart V, Petignat C, Francioli P, Troillet N: Laparoscope use and surgical site infections in digestive surgery. Ann Surg 2008, 247:627-632.

26. Wick EC, Gibbs L, Indorf LA, Varma MG, Garcia-Aguilar J: Implementation of quality measures to reduce surgical site infection in colorectal patients. Dis Colon Rectum 2008, 51:1004-1009.

27. Serra-Aracil X, Garcia-Domingo MI, Pares D, Espin-Basany E, Biondo S, Guirao $X$, Orrego C, Sitges-Serra A: Surgical site infection in elective operations for colorectal cancer after the application of preventive measures. Arch Surg 2011, 146:606-612.

28. Tang R, Chen HH, Wang YL, Changchien CR, Chen JS, Hsu KC, Chiang JM, Wang JY: Risk factors for surgical site infection after elective resection of the colon and rectum: a single-center prospective study of 2,809 consecutive patients. Ann Surg 2001, 234:181-189.

29. Kwaan MR, Sirany AM, Rothenberger DA, Madoff RD: Abdominal wall thickness: is it associated with superficial and deep incisional surgical site infection after colorectal surgery? Surg Infect (Larchmt) 2013, 14:363-368.

30. Drosdeck J, Harzman A, Suzo A, Arnold M, Abdel-Rasoul M, Husain S: Multivariate analysis of risk factors for surgical site infection after laparoscopic colorectal surgery. Surg Endosc 2013, 27:4574-4580

31. Anthony T, Murray BW, Sum-Ping JT, Lenkovsky F, Vornik VD, Parker BJ, McFarlin JE, Hartless K, Huerta S: Evaluating an evidence-based bundle for preventing surgical site infection: a randomized trial. Arch Surg 2011, 146:263-269.

32. Blumetti J, Luu M, Sarosi G, Hartless K, McFarlin J, Parker B, Dineen S, Huerta S, Asolati M, Varela E, Anthony T: Surgical site infections after colorectal surgery: do risk factors vary depending on the type of infection considered? Surgery 2007, 142:704-711.

33. Crolla RM, van der Laan L, Veen EJ, Hendriks Y, Van Schendel C, Kluytmans J: Reduction of surgical site infections after implementation of a bundle of care. PLoS One 2012, 7:e44599.

34. Tang CL, Jayne DG, Seow-Choen F, Ng YY, Eu KW, Mustapha N: A randomized controlled trial of $0.5 \%$ ferric hyaluronate gel (Intergel) in the prevention of adhesions following abdominal surgery. Ann Surg 2006, 243:449-455.

35. Neudecker J, Klein F, Bittner R, Carus T, Stroux A, Schwenk W: Short-term outcomes from a prospective randomized trial comparing laparoscopic and open surgery for colorectal cancer. Br J Surg 2009, 96:1458-1467.

36. Diamond MP: Reduction of adhesions after uterine myomectomy by Seprafilm membrane (HAL-F): a blinded, prospective, randomized, multicenter clinical study. Seprafilm Adhesion Study Group. Fertil Steril 1996, 66:904-910.

37. Fushiki H, Ikoma T, Kobayashi $H$, Yoshimoto $H$ : Efficacy of Seprafilm as an adhesion prevention barrier in cesarean sections. Obstet Gynecol Treatment 2005, 91:557-561.
38. Adept Adhesion Reduction Solution (4\% Icodextrin). Information for Prescribers. [http://www.baxterbiosurgery.com/us/resources/pdfs/adept/ADEPT_ Instructions_For_Use.pdf]

39. Gago LA, Saed GM, Chauhan S, Elhammady EF, Diamond MP: Seprafilm (modified hyaluronic acid and carboxymethylcellulose) acts as a physical barrier. Fertil Steril 2003, 80:612-616.

40. Lim R, Morrill JM, Lynch RC, Reed KL, Gower AC, Leeman SE, Stucchi AF, Becker JM: Practical limitations of bioresorbable membranes in the prevention of intra-abdominal adhesions. J Gastrointest Surg 2009, 13:35-41. Discussion 41-32.

41. Otake K, Uchida K, Yoshiyama S, Inoue M, Okita Y, Watanabe H, Inoue Y, Mohri $Y$, Miki C, Kusunoki M: Effects of a hyaluronate-carboxymethylcellulose membrane (Seprafilm) on human polymorphonuclear neutrophil functions. J Surg Res 2008, 149:243-249.

42. Toole BP, Wight TN, Tammi Ml: Hyaluronan-cell interactions in cancer and vascular disease. J Biol Chem 2002, 277:4593-4596.

43. Tzianabos AO, Cisneros RL, Gershkovich J, Johnson J, Miller RJ, Burns JW, Onderdonk AB: Effect of surgical adhesion reduction devices on the propagation of experimental intra-abdominal infection. Arch Surg 1999, 134:1254-1259.

doi:10.1186/1745-6215-15-413

Cite this article as: Berdah et al: A multicentre, randomised, controlled trial to assess the safety, ease of use, and reliability of hyaluronic acid/ carboxymethylcellulose powder adhesion barrier versus no barrier in colorectal laparoscopic surgery. Trials 2014 15:413.

\section{Submit your next manuscript to BioMed Central and take full advantage of:}

- Convenient online submission

- Thorough peer review

- No space constraints or color figure charges

- Immediate publication on acceptance

- Inclusion in PubMed, CAS, Scopus and Google Scholar

- Research which is freely available for redistribution 